\title{
Determination of the Turkish Language Sounds that Arabic Native Speaker Students Experience Problems With and Proposed ${ }^{*}$
}

\author{
Yusuf Sülükçü \\ Correspondence: Yusuf Sülükçü, Necmettin Erbakan University, Faculty of Education, A Blok 4/421 Meram, Konya, \\ Turkey.
}

Received: July 23, 2018

doi:10.11114/jets.v6i11.3472
Accepted: October 16, 2018

Online Published: October 17, 2018

URL: https://doi.org/10.11114/jets.v6i11.3472

\begin{abstract}
The present study aimed to identify Turkish language sounds that Arabic native speakers experience pronunciation difficulties with when learning Turkish and make various suggestions on how to resolve this problem. Qualitative research method and observation technique were used in the study. The data were collected in 2016 and the second half of 2017. The study population included native Arabic speakers who learned Turkish as a foreign language in Turkey, the study sample included 20 students attending Necmettin Erbakan University Turkish Instruction Application and Research Center (KONDIL) and 15 students attending a private course. It was determined that the students experienced

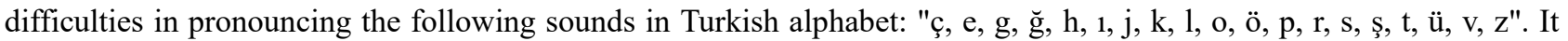
was also determined that it was possible to correct certain pronunciation mistakes in the above-mentioned sounds easily while correction of others took longer. It was found that the educational level of the student before learning Turkish was not effective in the pronunciation of the sounds, speaking a foreign language other than Turkish decreased the number of sounds where the students experienced problems and the gender factor had no impact on pronunciation of the sounds. It was determined that the comparison of the articulation points in the native language of the student and Turkish and practical demonstration of these articulation points and repetition of a large number of sounds resolved the problem to a great extent. It was recommended to focus more on the determined sounds in the instruction of the sounds in Turkish.
\end{abstract}

Keywords: Turkish as a foreign language, pronunciation, Arabic native speaker students, foreign language education

\section{Introduction}

\subsection{Introduce the Problem}

Voices are the first ring in the chain of language skills that are necessary for an individual to comprehend the world. After the $18^{\text {th }}$ week of pregnancy when they start to hear the sounds, humans begin to hear in the uterus (Murkoff, 2017; Timmons, 2018) and children learn to imitate the native language sounds by listening the sounds around them and processing these sounds in the subconscious. Pronunciation is defined as overall movements of the speech organs during the production of the sounds in the language, spoken words, and the voicing of the sounds based on articulation movements (BSTS / Grammar Terminology Dictionary, 2003).

The fact that an adult cannot reproduce certain sounds in a foreign language accurately despite immense efforts and cannot speak a foreign language similar to her or his native language despite the exceptions, her or his accent revealing that the spoken language was learned as a second language lead to the question that whether there is a suitable age for the accurate imitation and pronunciation of the sounds. Two different concepts were developed based on this question as "language acquisition" and "language learning". The notion of "language acquisition" reflects the learning of a language by the individual - especially a child - through the subconscious without the systematic instruction of grammar or the processes in a language (Krashen, 1981), and "language learning" includes conscious efforts by an individual to learn a foreign language.

Chomsky claimed that humans have an instinctive language learning ability he called the Language Acquisition Device (LAD) in his "Universal Grammar" theory (Chomsky, 2010; karmakitap, 2018). According to him, this language ability symbolizes a mental potential that embodies systematic language codes. Chomsky stated that the child should be xposed

*This article was presented orally at UBEK ICSE 2018 International Science and Education Congress held in Afyonkarahisar on March 23-25, 2018. 
to a language sufficiently for the device to kick in. Chomsky argued that the language is present in this system as a "skeleton", and the child dresses up this skeleton with the colors and patterns of the language that he or she was born into. The native language is the first garment worn by this skeleton that shapes it (Uçak, 2016). Chomsky argued that the functions of the language acquisition device continues until adolescence and then ceases to function.

Krashen shared the same views with Chomsky on the language acquisition device and the skeleton, however, contrary to Chomsky, he had different views on the language acquisition of adults. Chomsky argued that individuals who enter adulthood can no longer use LAD, while Krashen argued that LAD is available during the whole life. According to Krashen, if the adequate environment is available, LAD would resume its function. Thus, according to Chomsky, adults cannot acquire but learn a language, while according to Krashen, adults can both acquire and learn a language (Krashen, $1981 ; 1982 ; 2002)$.

The age where the individual could imitate and pronounce the sounds accurately is known to differ among individuals. According to Long (1990), 1993) and Scovel (1988), learners who were not exposed to the target language before puberty could not pronounce sounds similar to the native speakers of that language. Certain researchers disagreed on the effect of the age factor on pronunciation. They stated that some students with neurocognitive flexibility and very high motivation could develop a pronunciation similar to the native speakers even if they were not exposed to the target language before puberty (Bongaerts, van Summeren, Planken, \& Schils, 1997). However, foreign accents were observed even in individuals who started to learn the second language during childhood (Flege, Munro and MacKay, 1995).

It is possible for some children born with hearing impairment due to some reason to regain the hearing ability with the aid of various medical devices. However, as the age of treatment is delayed, the ability to produce the sounds accurately decreases. Although this does not seem to support Chomsky's approach, when it is considered that no auxiliary device could record and transmit the sounds to the brain like the human ear, the question that whether this is due to the weakening of the learning ability of the brain (LAD) in time or the inability to transmit the sounds accurately and completely to the brain would remain as a question that could only be answered by future advanced medical studies. However, the language is not merely a collection of sound and in fact, it is a mental process and when the individual is sufficiently exposed to a language such as the case of Turkish guest workers in Germany, the brain could form the required codes and a foreign language could be acquired without a systematic language instruction. This fact supports Krashen's approach.

In a study conducted in Finland, it was determined that high school students with musical skills could pronounce sounds better than non-musical students, and that there was a positive correlation between pronunciation and musical skills (Milovanov Päivi, Pietilä, Tervaniemi and Esquef, 2010). Furthermore, it was stated that the phonemic similarity between the mother tongue and the target language had an effect on pronunciation (Wiik, 1965, Flege, 1988, Lintunen, 2004).

When learning a foreign language, the first objective is to learn the sounds of the target language. The subject matter of the scientific field called phonetics or phonology is the sounds that people use during speech. Sound is the most basic element of any language, and proper pronunciation is crucial to avoid misunderstandings in communication. Thus, phonetics is a priority in foreign language learning and instruction.

It is observed that there is a growing interest in learning Turkish globally. Furthermore, the share of the individuals who came to Turkey for educational purposes is high in this global interest. In 2011, there were 31,170 foreign students in Turkish colleges in 2001 and this figure reached 103,727 in the 2016-2017 academic year according to the 2016 Migration Report (T. R. Ministry of the Interior, 2017). Besides the normal interest to learn Turkish, there was a serious increase in the number of individuals who desire to learn Turkish due to necessities. Due to the civil war in Syria and the turmoil in Iraq, there is a serious population of immigrants in Turkey expressed in millions.

This immigration was considered to last for a short period of time in the beginning; however, the extension of the immigration status of these individuals introduced the problem of their education. According to UNICEF (2015) figures, there were 1,938,999 Syrians in Turkey as of September 2015 including 1,047,000 children, which is 54\% of all Syrian refugees. According to the Ministry of National Education (MNE) data, the number of officially registered Syrian students in Turkey during the 2017-2018 academic year is presented in Table 1. 
Table 1. Syrian students in Turkish education system

\begin{tabular}{lccc}
\hline & Public Schools & Temporary Educational Centers & Total \\
\hline Preschool (Age 5) & 29.281 & 7.063 & 36.344 \\
1st Grade (Age 6) & 99.298 & 14.139 & 113.437 \\
2nd Grade (Age 7) & 68.177 & 13.348 & 81.525 \\
3rd Grade (Age 8) & 38.158 & 65.496 & 103.654 \\
4th Grade (Age 9) & 30.226 & 44.716 & 74.942 \\
5th Grade (Age 10) & 44.091 & 7.107 & 51.198 \\
6th Grade (Age 11) & 20.509 & 13.677 & 34.186 \\
7th Grade (Age 12) & 10.908 & 17.718 & 28.626 \\
8th Grade (Age 13) & 7.385 & 15.287 & 22.672 \\
9th Grade (Age 14) & 14.188 & 2.375 & 16.563 \\
10th Grade (Age 15) & 6.022 & 5.234 & 11.256 \\
11th Grade (Age 16) & 2.736 & 6.424 & 9.160 \\
12th Grade (Age 17) & 1.743 & 8.812 & 10.555 \\
Total & 372.722 & 221.396 & 594.118 \\
\hline
\end{tabular}

Pronunciation is a serious problem in the instruction of Turkish as a foreign language (Doğan, 2007; Paksoy and Dönmez, 2015; Şeref and Yılmaz, 2015). Because, there are several words in Turkish that are formed by close sounds such as "kar, ker, kvr, kir, kor, kör, kur, kür". Mispronunciation would lead to the misunderstanding of the word.

\subsection{Explore the Importance of the Problem}

The initial requirement was the development of specialized language material based on the needs of the target population in order to facilitate the efforts of the refugees in Turkey and those who are learning and teaching Turkish in general. Specialized materials would facilitate instruction and learning of the students since these would be specially developed to resolve the problems.

Tuncel (2015) reported that the leading concern among foreigners about learning Turkish was speech anxiety. This is an important problem, and the leading cause of this concern is the problem of pronunciation. According to Lado, we need to analyze and compare the pronunciation systems of the target language and the mother tongue to resolve the pronunciation problems (Cited by Dalak and Mercan, 2017).

The leading problem in the instruction of Turkish as a foreign language is the instruction of the language with correct pronunciation (Derman, 2010, Tüm, 2014). Although significant problems are not experienced in the pronunciation of the sounds that exist in the native languages of those who learn Turkish as a foreign language, the sounds unique to Turkish language lead to pronunciation problems. Identification of the sounds where students with different native languages experience difficulties and development of specialized Turkish material for learners with different native languages are important for an active instruction.

Determination of similarities and differences between Turkish and Arabic in terms of phonology, morphology, syntax and semantics, and organization of instructional strategies based on the determined principles would lead to an active instruction. Especially, it is very important to organize and match the phonetics of both languages for instruction. Because, in learning a foreign language, the transfer of the comparative model between the mother tongue and the target language helps the student to understand the rules more easily (Doğan, 2007).

Linguist Fries (1945) argued that the development of the most effective teaching material should be based on a careful comparison of the mother language of the learner and the scientific description of the target language.

In addition to being a requirement to teach Turkish more systematically as a foreign language, the topic of pronunciation of native Arabic speaker students became significant due to the immigration of about 3 million Syrians to Turkey as a result of the civil war and the integration of about 400.000 students who need education into the Turkish education system within the scope of PICTES Project (PICTES, 2018). The present study aimed to identify the Turkish sounds that Arabic native speaker learners experience problems with and present various recommendations on how to solve this problem.

Various studies were conducted on the pronunciation of learners of Turkish as a foreign language. In a study by Dönmez and Paksoy (2015), it was reported that the learners experienced problems in the pronunciation of vowels and certain letters in Turkish that does not have equivalents in Arabic. In a study by Şengül (2014), it was concluded that the learners experienced difficulties in articulation and writing the a, e, 1, i, o, ö, u, ü, c, ç, ğ, l, ş, y sounds/letters in the Turkish alphabet. In general, it was determined that the students confused the back and front articulation of these sounds/letters. Dalak and Mercan (2017) determined that Saudi students experienced difficulties in articulating the sounds of "ç, g, ğ, j, p, v". The reason why there were only a few sounds in the study was the fact that the study was conducted only on the sounds of j, p, v, 1, o, ö, ü, which existed in Turkish but not in the Arabic language. Only consonants were investigated in that study. In a similar study, Yılmaz and Şeref (2015) determined that the students 
experienced problems in the articulation of the $\mathrm{p}, \mathrm{u}, \mathrm{c}, 1, \mathrm{i}, \breve{\mathrm{g}}, 1, \mathrm{o}$ " sounds based on the study data.

In the present study, the following research questions were determined to solve the problem of how to instruct the Turkish sound easier and more accurately to students who are native Arabic speakers:

1. What are the sounds that Arabic native speaker students learning Turkish as a foreign language experience reading and pronunciation problems?

2. Does the educational level of the student have an impact on the sounds that the student experiences a pronunciation problem with?

3. Does the fact that the student speaks a foreign language other than Turkish have an impact on the sounds that the student experiences a pronunciation problem with?

4. Does the gender of the student have an impact on the sounds that $\mathrm{s} /$ he experiences a pronunciation problem with?

\section{Methodology}

\subsection{Research Sample}

The study population included Arabic native speakers who learn Turkish as a foreign language at A1 level in Turkey. In the study, homogeneous sampling, a subcategory of the purposive sampling method, was used since the study required to work with a homogeneous group. Purposive sampling is used when non-probabilistic selection of participants with certain characteristics is required (Black, 2010) and it is also known as a judgmental, selective and subjective method (Crossman, 2018). Homogeneous sampling was considered adequate for the study since it is used in studies where all subjects in the sample are required to be similar and it is necessary to focus on a particular subgroup such as a particular occupation or level in an organizational hierarchy (Saunders, Lewis \& Thornhill, 2012). The study sample included 53 Arabic native speaker learners attending Turkish as a foreign language courses at Necmettin Erbakan University KONDIL in 2016 and 15 students who were learning Turkish as a foreign language in a private course in 2017. The sample included citizens of Syria, Iraq, Somalia and Yemen. Of the students in the sample, 23 were female and 30 were male.

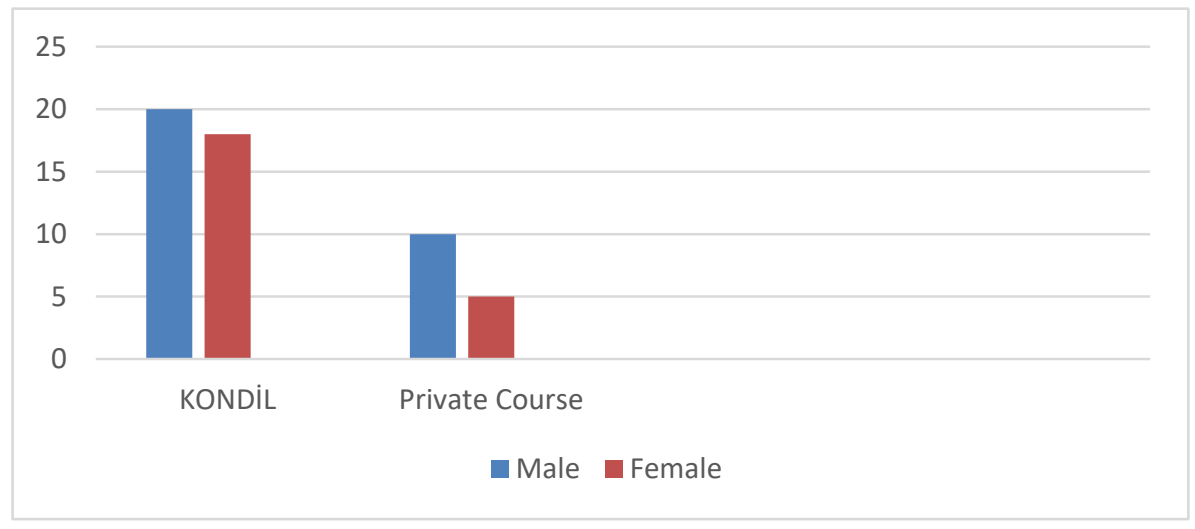

Figure 1. The Study Group

\subsection{Data Collection Tools}

The research was conducted with the qualitative research method. The data were collected by the researcher through observations in 2016 and 2017. The observation technique is described as the process of careful, planned and meticulous observation and analysis of an event, a fact, or an object. It is used to learn and know its qualities, the information and value obtained from such an analysis, and the scientific method that is applied in all scientific fields using various tools and instruments to discover the causes of phenomena is one of the indispensable data collection instruments in both qualitative and quantitative studies (Yıldırım and Şimşek: 2005; Alacapınar, 2011).

The data were collected with the method described below:

To determine how individual voices were pronounced, students were asked to pronounce the letters during the alphabet instruction, and the pronunciation of the learners was recorded with a voice recording device.

The reading texts used as data collection instruments were the texts included in the textbook titled "Turkish Course Textbook for Foreigners A1". The vocalization of these sounds by the students was recorded with a voice recording device during the classes. 
The voice recordings were listened to determine pronunciation errors, in addition to the researcher's knowledge on the pronunciation of the Turkish and Arabic sounds and the articulation points for these sounds, Arabic language experts were consulted when necessary. Furthermore, the pronunciation of Arabic sounds by the students were compared with the pronunciations provided on the web site "Forvo" (www.forvo.com, 2018). The sounds and pronunciations that were considered wrong were marked separately for each learner.

To determine the effect of their native Arabic on the Turkish pronunciation of the students, these recordings were listened by the researchers and whether Arabic or Turkish articulation points were used was identified. Several learners were asked to repeat the same words to improve reliability based on the probability of the students to make pronunciation mistakes.

Furthermore, semi-structured interviews were conducted with the students who completed A1 level and the students were asked why they experienced problems in pronouncing Turkish sounds and which sounds they experienced problems with using open-ended questions to improve the validity and reliability of the findings and interpretations. The semi-structured interview technique is a method used to allow the responders to freely express their views on a particular topic and used to develop a new perspective on the research, to confirm a hypothesis, or to better explain the current situation (Bernard, 2000; leCompte and Schensul, 1999; Zorn, 2010).

\section{Results}

In conclusion, it was determined that the native Arabic speaker students experienced problems in the pronunciation of 15 consonants and 6 vowels, a total of 21 sounds in the Turkish alphabet. The consonants and vowels that the students experienced pronunciation problems with are presented in Table 2 .

Table 2: The consonants that native Arabic speaker students experienced pronunciation problems with

\begin{tabular}{ccccc}
\hline & \multicolumn{2}{c}{ Correct } & \multicolumn{2}{c}{ Incorrect } \\
\hline Consonants with pronunciation errors & $\mathrm{f}$ & $\%$ & $\mathrm{f}$ & $\%$ \\
\hline $\mathrm{c}$ & 0 & 0 & 53 & 100 \\
$\mathrm{~g}$ & 0 & 0 & 53 & 100 \\
$\breve{\mathrm{g}}$ & 0 & 0 & 53 & 100 \\
$\mathrm{~h}$ & 0 & 0 & 53 & 100 \\
$\mathrm{j}$ & 0 & 0 & 53 & 100 \\
$\mathrm{k}$ & 0 & 0 & 53 & 100 \\
$\mathrm{l}$ & 0 & 0 & 53 & 100 \\
$\mathrm{p}$ & 0 & 0 & 53 & 100 \\
$\mathrm{r}$ & 0 & 0 & 53 & 100 \\
$\mathrm{~s}$ & 0 & 0 & 53 & 100 \\
$\mathrm{~s}$ & 36 & 67.9 & 17 & 32.1 \\
$\mathrm{t}$ & 0 & 0 & 53 & 100 \\
$\mathrm{v}$ & 0 & 0 & 53 & 100 \\
$\mathrm{y}$ & 5 & 9.4 & 48 & 90.6 \\
$\mathrm{z}$ & 0 & 0 & 53 & 100 \\
\hline
\end{tabular}

Based on the observations and recordings, the students experienced difficulties in pronouncing 15 out of 21 consonants in the Turkish alphabet.

Table 3. The vowels that native Arabic speaker students experienced pronunciation problems with

\begin{tabular}{ccccc}
\hline & \multicolumn{2}{c}{ Correct } & \multicolumn{2}{c}{ Incorrect } \\
\hline Vowels with pronunciation errors & $\mathrm{f}$ & $\%$ & $\mathrm{f}$ & $\%$ \\
\hline $\mathrm{e}$ & 0 & 0 & 53 & 100 \\
1 & 0 & 0 & 53 & 100 \\
$\mathrm{o}$ & 0 & 0 & 53 & 100 \\
$\ddot{\mathrm{o}}$ & 0 & 0 & 53 & 100 \\
$\mathrm{u}$ & 0 & 0 & 53 & 100 \\
$\ddot{\mathrm{u}}$ & 0 & 0 & 53 & 100 \\
\hline
\end{tabular}

Based on the observations and recordings, the students experienced difficulties in pronouncing 6 out of 8 vowels in the Turkish alphabet.

As seen in Tables 2 and 3, no learners experienced problems in the pronunciation of vowels "a" and " $\mathrm{i}$ " and the consonants "b, c, d, m. and n."

It was found that the reason for the high frequency of errors in sounds that existed in Arabic was the fact that the sounds with similar origins corresponded to a single letter in Turkish.

Furthermore, students made errors in the pronunciation of the sounds in Turkish words with Arabic origins.

The pronunciation difficulties and errors made in the above-mentioned sounds could be grouped under three categories: 
- The lack of the target language sound in the native language,

- Negative transfer caused by the similarity of the sound in the target and native languages,

- Generalization of a pronunciation learned in the target language to all words.

The problem experienced by the learners due to their inability to find the articulation point of the sound due to the lack of this sound in their native language was resolved by identification and display of the accurate articulation points and repetition until the accurate sounds were vocalized.

The second problem was the negative transfer caused by the similarity of the sound in the target and native languages. Positive transfer is the positive impact of a previous learning to a subsequent learning situation and negative transfer is the negative impact of a previous learning to a subsequent learning (Omrad, 2014; Singley and Anderson, 1989; Woltz, Gardner and Bell, 2000). Transfer leads to both positive and negative consequences in language education, similar to other types of education. The students conducted both positive and negative transfer during the study. Positive transfer cases were enforced, while negative transfer cases were corrected immediately to prevent incorrect learning.

The present study findings were consistent with Ghee Seah's (1981) classification of errors in written expression when learning foreign languages. It was observed that Seah's classification errors were not limited to written expression, but the same errors were observed in pronunciation as well. Seah's classification was as follows:

1. Inter-lingual Errors: This type of error is also referred to as transfer errors. These errors are usually made by transferring the thoughts in the native language exactly to the target language.

2. Intra-lingual Errors: These errors are not due to the influence of a previously acquired language. These errors are due to the alienation of the student with the structure, features and rules of the target language and the lack of the internalization of the concepts inherent in the target language.

3. Developmental Errors: These errors are more like a subdivision of intra-lingual errors. These errors could occur due the limitation of the association that the learner establishes with the target language by the in-classroom experiences, the textbook, and own studies of the student. There is little difference between these errors intra-lingual errors.

The problems experienced in the pronunciation of the above-mentioned sounds by the students are detailed below.

\subsection{Consonants}

\subsubsection{The Sound "ç"}

The sound "ç" is one of the sounds not found in the Arabic language. The difficulty experienced in the pronunciation of this sound was the lack of the sound in their native language. It was determined that the pronunciation of "ç" is mostly confused with the sound "ş" and it took some time for the students to pronounce the sound correctly. It was observed that most students in the sample learned to pronounce the sound in a short period of time, while a student from Somalia was not able to produce this sound for a long time (seven weeks).

\subsubsection{The Sound "g"}

Based on the collected data, pronunciation difficulties experienced with this sound was due to the lack of this sound in Arabic. However, the pronunciation difficulties associated with this sound were easily resolved by identification of the articulation point and repetitions.

\subsubsection{The Sound " $\breve{\mathrm{g}}$ "}

Despite the fact that the close equivalent of this sound, " $\dot{\varepsilon}$ exists in Arabic language, difficulties were experienced with the pronunciation of this sound. Based on the observations, this sound, which is subtly pronounced with a lower accent in Turkish, was pronounced with a stronger accent by the learners. It was found that the reason of this pronunciation difficulty was the apparent and strong pronunciation of the " $"$ " sound in Arabic, and the erroneous sound transfer from the students' mother tongue to the target language. It was also found that this sound was perceived with difficulties during listening and dictation studies.

\subsubsection{The Sound "h"}

The fact that there are three "h" sounds in Arabic in addition to "॰" including the articulated $\mathrm{h} " \mathrm{\tau}$ " and the stertorous ch, while there is only a single "h" in Turkish lead to a confusion among students about which "h" in Arabic does the one in Turkish correspond to and whether there are other sounds in Turkish that correspond to the remaining "h" sounds in Arabic. In addition to the back vowels, they made the mistake of pronouncing the Arabic " $ح$ ". The learners were informed that the sound corresponds to the letter " $\boldsymbol{\nabla}$ " in Arabic and the confusion was immediately resolved.

\subsubsection{The Sound "j"}

"J" is one of the sounds that do not exist in Arabic, similar to "ç". As to the reason for the pronunciation difficulties 
experienced with this sound, the lack of the sound in their mother tongue could be suggested. It was observed that it was mostly pronounced like the sound "ş", and it took a while to correct the pronunciation of this sound.

\subsubsection{The Sound " $k$ "}

While it was considered that there would not be any pronunciation problems with this sound since it exists in Arabic as well, hesitations and false pronunciations were observed among students due to erroneous transfer since the sound had both back and front versions in their native language. During the initial instruction about the alphabet, the sound "k" was explained with the Arabic "ق" and "sounds and while instructing the vowels and their characteristics, the information on the sound was reinforced by stating that it is pronounced back with back vowels and front with the front vowels and the erroneous pronunciation was easily corrected. However, the point of articulation of "ك" in Arabic is somewhat at the back when compared to Turkish. During reading, this difference in origin could be noticed, albeit a little.

\subsubsection{The Sound "l"}

The problems experienced in pronunciation of the sound "1", which is easy to articulate and available in Arabic, were also related to back and front articulation point. As is known, in addition to the sound "l", which is articulated at the back with back vowels and at the front with the front vowels, there is also another "front l" sound in words transferred from foreign languages and all these sounds are represented by a single letter in Turkish alphabet. The learners mispronounced the "l" sound, which should be articulated at the front although it is with back vowels such as "rol, plan, lale, etc." The fact that there is no accent that indicates the front articulation of the "1" sound led to mispronunciation of the "l" voice, especially during the reading sessions.

\subsubsection{The Sound "p"}

The "p" sound, which does not exist in Arabic language, was one of the sounds that the learners experienced the greatest difficulty with. It was observed that they continued to mispronounce the sound after they learned its pronunciation and even after the A1 course was completed. Instead of this sound, they continued to articulate a sound very close to "b" but fainter and more accented.

\subsubsection{The Sound " $r$ "}

This is a sound with two different pronunciations and a unique rule in Arabic. The mispronunciations were easily corrected by stating that it is articulated from the back with back vowels and at the front with front vowels in Turkish instead of the unique rule in Arabic.

\subsubsection{The Sound "s"}

It is one of the sounds confused by the students due to the fact that there are three different "s" sounds in Arabic, even though the students did not experience pronunciation problems during the instruction of the sounds. During these instructions, mispronunciations were eliminated by stating that there is no sound in Turkish similar to lisped " $"$ " and the sound "s" is articulated like the sound "س" (sîn) with front vowels and like "ص" (sâd) with back vowels.

\subsubsection{The Sound "ş"}

Although this sound exists in Arabic, it is articulated at the back when compared to Turkish. The learners articulated this sound at the back, similar to Arabic, and sometimes they confused it with the sound "ç".

\subsubsection{The Sound "v"}

One of the sounds that do not have a full equivalent in Turkish language is the "v", although it seems that it exists in Turkish. This sound can be considered as the equivalent of the English "w" sound and it is a double lip consonant in Arabic. It is articulated by rounding the lips. The sound " $\mathrm{v}$ " in Turkish is a palato-labial consonant and the lips are not rounded during articulation. The sound " $v$ " was pronounced significantly as a double lip consonant through erroneous transfer during the pronunciation of the conjunction " $v e$ " (and) and correction by repetitions took some time.

\subsubsection{The Sound "y"}

The sound "y", which is considered as a semi-vowel sound, is used both as a vowel and consonant in Arabic. This is one of the sounds that the learners experienced pronunciation problems with because this sound is used both as a vowel and consonant in Arabic. Although it was stated that this sound is only a consonant in Turkish, sometimes it was observed that they continued to pronounce it as the sound "i".

\subsubsection{The Sound "z"}

Similar to the sound "s", $\mathrm{z}$ corresponds to more than one similar sounds in Arabic. There are three different "z" sounds in the Arabic language, one of which is the lisped "ذ", except the sound "ض", which is sometimes articulated as "z" 
(ramazan, etc.) and sometimes with "d" (darbe, etc.) in Turkish. It was stated to the students that in Turkish, it is articulates as Arabic " $"$ "with front vowels and as "ظ " with back vowels. Although the pronunciation of "ظ Arabic language has the same origin, there is a slight difference in sound due to the use of the tip of the tongue in Arabic.

\subsection{Vowels}

There are three vowels in Arabic; a, i and $\mathrm{u}$. These are written with the letters elif, yâ and wav, and the movements called üstün (fetha), esre (kesre) and ötre (zamme) in Turkish. However, similar to other languages, the vowels are articulated differently with back and front sounds in Arabic. The "a" voice has two forms articulated at the back and the front and when used with back sounds, the sound " $i$ " is articulated similar to the sound " 1 " in Turkish. When we consider the sound "u", it can be argued that there are four common vowels in Arabic and Turkish. Below, the pronunciation problems experienced by the students with vowels and their causes are listed.

\subsubsection{The Sound "e"}

It is one of the sounds that do not have any equivalent in Arabic. This sound is often pronounced as frontal "a" in Arabic. It was also pronounced as the "i" in English by some students who speak English. While these were comprehensible reasons, some students pronounced it as the sound "ye" as it is articulated at the beginning of the word in the Cyrillic alphabet. Since these learners did not know the Cyrillic alphabet, it was not clear why that happened.

\subsubsection{The Sound "1"}

The sound " 1 " is articulated involuntarily during the use of consonants with esre (strât, zıll, zırar, etc.), however, there is no corresponding letter in the Arabic alphabet. Thus, in the initial stages of instruction, learners experienced problems in the articulation of this sound, however, after providing a few Arabic examples that contained the sound " 1 ", the students were able to pronounce the sound correctly.

\subsubsection{The Sound "o"}

This is another vowel that native Arabic speaker students experienced difficulty with. There was a continuous tendency to pronounce it like the sound " $\mathrm{u}$ " and it took some time to correct this.

\subsubsection{The Sound "ö"}

This is another vowel that the students experienced difficulty with. It took some time to correct the pronunciation and it was not possible to correct it completely and students continued to articulate it at the back.

\subsubsection{The Sound "ü"}

The Turkish sound that most learners of Turkish as a foreign language experience problem with independent of their native language is the sound "ü". Even the students who have been living in Turkey for 7-8 years cannot pronounce this sound accurately.

\section{Discussion and Conclusions}

Based on the findings reported in above-mentioned studies, it was observed that the sounds that the participants of the present study experienced difficulties with (ç, e, g, $\breve{g}, \mathrm{~h}, \mathrm{l}, \mathrm{j}, \mathrm{k}, \mathrm{l}, \mathrm{o}, \ddot{\mathrm{o}}, \mathrm{p}, \mathrm{r}, \mathrm{s}, \mathrm{s}, \mathrm{t}, \mathrm{u}, \ddot{\mathrm{u}}, \mathrm{v}, \mathrm{y}, \mathrm{z}$ ) were mostly similar to these study findings.

The previous studies and findings of these studies previously are presented in the table below:

Table 4. Comparison of the sounds that learners experienced pronunciation difficulties/problems with as reported in similar studies

\begin{tabular}{|c|c|c|c|c|c|c|c|c|c|c|c|c|c|c|c|c|}
\hline \multicolumn{17}{|c|}{ Consonants where pronunciation errors were determined } \\
\hline Sülükçü & & ç & $\mathrm{g}$ & $\breve{\mathrm{g}}$ & $\mathrm{h}$ & $\mathrm{j}$ & $\mathrm{k}$ & 1 & $\mathrm{p}$ & $\mathrm{r}$ & $\mathrm{s}$ & ş & $\mathrm{t}$ & $\mathrm{v}$ & $\mathrm{y}$ & $\mathrm{Z}$ \\
\hline Şengül & $\mathrm{c}$ & ç & & $\breve{\mathrm{g}}$ & & & & 1 & & & & Ş & & & $\mathrm{y}$ & \\
\hline Dalak and Mercan & & ç & $\mathrm{g}$ & $\breve{\mathrm{g}}$ & & $\mathrm{j}$ & & & $\mathrm{p}$ & & & & & $\mathrm{v}$ & & \\
\hline Y1lmaz and Șeref & $\mathrm{c}$ & & & $\breve{\mathrm{g}}$ & & & & 1 & & & & & & & & \\
\hline Dönmez and Paksoy & $\mathrm{c}$ & ç & $\mathrm{g}$ & $\breve{\mathrm{g}}$ & & $\mathrm{j}$ & $\mathrm{k}$ & 1 & & & & & & $\mathrm{v}$ & & \\
\hline \multicolumn{17}{|c|}{ Vowels where pronunciation errors were determined } \\
\hline Sülükçü & & & $\mathrm{e}$ & & 1 & & $\mathrm{i}$ & & $\mathrm{o}$ & & $\ddot{0}$ & & $\mathrm{u}$ & & $\ddot{\mathrm{u}}$ & \\
\hline Şengül & $\mathrm{a}$ & & $\mathrm{e}$ & & 1 & & $\mathrm{i}$ & & o & & $\ddot{o}$ & & $\mathrm{u}$ & & $\ddot{\mathrm{u}}$ & \\
\hline Yilmaz and Şeref & & & & & 1 & & $\mathrm{i}$ & & o & & $\ddot{\mathrm{o}}$ & & & & & \\
\hline Dönmez and Paksoy & $\mathrm{a}$ & & $\mathrm{e}$ & & 1 & & $\mathrm{i}$ & & o & & $\ddot{o}$ & & $\mathrm{u}$ & & $\ddot{\mathrm{u}}$ & \\
\hline
\end{tabular}

The table demonstrates that the highest number of errors on consonants was determined in the present study, on the other hand, Dönmez and Paksoy (2015); Şengül determined errors in all vowels.

In general, it was possible to correct the questions and problems related to the sounds related to "g, g, h, k, l, r, s, t, v, y, $\mathrm{z}$, i" sounds that were determined as pronunciation difficulties and errors with a few explanations, however it took 
longer to correct the mispronunciation of the "ç, e, $1, \mathrm{j}, \mathrm{o}, \mathrm{u}, \mathrm{s}^{\prime}$ sounds. It was not possible to improve the pronunciation of "p, $\ddot{o}, \ddot{u} "$ sounds to the desired levels during the A1 course period.

The most noticeable among these sounds was "p", which was expected to be easy to pronounce, but was pronounced as " $b$ " even a month after the beginning of the instructions. This is an interlingua type of error The same was also mentioned by Dalak and Mercan (2017): "[p] was the most difficult sound to improve in our study. In the pre-test, when [p] was in the first sound of the word, the success rate was $20 \%$, it was $40 \%$ when [p] was in the middle sound, and $45 \%$ when [p] was in the last sound. Pre-test results demonstrated that subjects used the [b] voice, which they transferred from their mother tongue, instead of the [p] voice in the target language. Based on the post-training post-test results, the success rate increased to $45 \%$ when [p] is pronounced in the first sound, to $100 \%$ when used in the middle sound, and to $90 \%$ when used in the last sound. However, when [p] was used as the first sound, even at the end of the instruction process, success was mediocre at best."

The measures that should be taken to correct the pronunciation of the sounds that were determined to be difficult could be listed as follows based on the techniques applied in the present study and previous studies on the topic:

It was determined that the learners comprehend sounds more easily with comparison. According to Lado, learners experience the greatest difficulty in learning the phenomena that exist in the target language, but do not exist in their native language. Thus, knowing the differences and similarities between the mother tongue and the target language would help us to anticipate the problems that might arise during learning and accordingly improve our instruction, because the similarities between the two languages would facilitate learning, while the differences would lead to difficulties for the learners (Dalak and Mercan, 2017). Therefore, it is very important to provide information for the teachers about the Arabic sounds, their articulation points and their pronunciation for the instruction of accurate pronunciation to native Arabic speaker students.

During the instruction of the alphabet, all sounds should be articulated initially by the instructor, paying close attention to the articulation points, then the learners should pronounce these sounds separately and the learners should be listened very carefully. The source of the error made by each listener when pronouncing the sound, namely the throat, larynx, tongue or lips, should be determined. If there is a common language that the instructor and the learner could speak, this should be used, otherwise, the cause of the error should be explained with body and sign languages, and extensive and loud repetitions should be conducted.

The fact that sounds like "t, k, s" which are found in two different forms such as back and front and depicted with two different letters in the Arabic alphabet but represented by a single letter in Turkish although reflecting two different sounds lead to pronunciation problems. Thus, it should be mentioned during the instruction of the letters which are depicted with only one letter in Turkish but correspond to two different sounds that these sounds correspond to back sounds in Arabic when used with back vowels and correspond to the front sounds in Arabic when used with front sounds. Thus, it was possible to correct the learners' pronunciation errors easily.

It is possible to group the sounds that do not exist in Arabic, but exist in the target Turkish language, in two categories: those that do not have any equivalents, and the sounds that exist in the language of speech but not in the Arabic alphabet. For the instruction of sounds in the second category, the most adequate method is to find the words that include these sounds and match these sounds with the Turkish sounds and during the present study, it was found that the method was successful. As an example, the use of the word "strat" for comprehension of the sound " 1 " facilitated learning.

In correction of the pronunciations of vowel sounds, the impact of the articulation organs such as the tongue, lips and jaws on the sounds should be demonstrated. It was determined that it was difficult to pronounce the sounds which are difficult to articulate in Turkish and do not have an equivalent in Arabic such as the "ü" sound alone, but these were pronounced more easily when used in a word. It would be better to try to articulate the sound in a word instead of forcing the students to pronounce the sound by itself during the instruction of these sounds. Several learners in the present study were able to pronounce the voices easily as a result of the above-mentioned method.

In the instruction of textbooks with Turkish as a foreign language, alphabet is mentioned very briefly, and after the completion of alphabet instructions, the topic is never mentioned again. This means that the significance of the repetition of the sounds is neglected in accurate instruction of the sounds. It should be reminded in textbooks that these sound should be repeated, and the instructors should frequently repeat the sounds which are especially difficult to pronounce. In improving mispronunciations, simple poems and rhymes also provide great benefits.

In order to avoid the negative transfer of the sound in the native language to the target language, it is necessary to conduct text reading exercises frequently with the learners and their mistakes should be corrected immediately after the learners complete the sentences. The biggest error encountered in the present study on erroneous transfer was in the articulation of the sound "v", which is a palato-labial consonant in Turkish, as a double lip consonant like in Arabic by 
rounding the lips. This problem has been solved by frequent warnings.

It was determined that an increase in the education level of the learners was not effective on the pronunciation of the sounds, fluency of the learners in a different foreign language other than Turkish reduced the number of sounds that the learner experienced problems with in Turkish and the gender factor did not have any impact on pronunciation difficulties and errors.

In the instruction of Turkish sounds, instructors should pay more attention to the words identified in the present study.

\section{References}

Bernard, R. (2000). Social Research Methods: Qualitative and Quantitative Approaches. Thousand Oaks, CA: Sage Publications.

Bongaerts, T., van Summeren, C., Planken, B., \& Schils, E. (1997). Age and ultimate attainment in the pronunciation of a foreign language. Studies in Second Language Acquisition, 19(4), 447-465. https://doi.org/10.1017/S0272263197004026

Chomsky, N. (2000). The architecture of language. Oxford: Oxford University Press.

Chomsky, N. (2014). Language and mind ( $3^{\text {rd }}$ ed.). NewYork: Cambridge University Press.

Chomsky, N. (2018, August 27). Tool Module: Chomsky's Universal Grammar. Retrieved from http://thebrain.mcgill.ca/flash/capsules/outil_rouge06.html

Crossman, A. (2018, June 22). Understanding Purposive Sampling. Retrieved from https://www.thoughtco.com/purposive-sampling-3026727

Dalak, H. D., \& Mercan, Ö. (2017). Error analysis of pronunciation in turkish consonant voices not existing in Arabic of Saudi learners. Kafkas University, e-Kafkas Journal of Educational Research, 4(2), 10-18. https://doi.org/10.30900/kafkasegt.308240

Dönmez, M. I., \& Paksoy, S. (2015). A survey on the problems confronted by the Syrian students during their Turkish courses they take in Turkey: Kilis 7 Aralik University sample. International Journal of Languages' Education and Teaching UDES 2015, 1907-1919. https://doi.org/10.18298/ijlet.366

Flege, J. E. (1988). The production and perception of foreign language Speech Sounds. In H. Winitz (Eds.), Human Communication and Its Disorders (pp. 225-401). NJ: Norwood. Retrieved from: http://www.jimflege.com/files/Flege_in_Winitz_1988_small.pdf

Flege, J. E., Munro, M. J., \& MacKay, I. R. A. (1995). Factors affecting strength of perceived foreign accent in a second language. Journal of the Acoustical Society of America, 97(5), 3125-3134. https://doi.org/10.1121/1.413041

Ghee, S, (1980). Contrastive Analysis, Error Analysis and Interlanguage in Relation to Adult Chinese Speakers Learning English As a Second Language (Ph. D. Thesis, Simon Fraser University, Canada). Retrieved from http://summit.sfu.ca/system/files/iritems1/3917/b12509668.pdf

Grant, A. (2015, June 25). The 4 most important elements of your voice. Retrieved from https://www.fastcompany.com/3047183/the-4-most-important-elements-of-your-voice

Krashen, S. (1982). Principles and practice in second language acquisition. Oxford: Pergamon Press.

Krashen, S. (2002). Second language acquisition and second language learning. California, Pergamon Press.

Lado, R. (1951). Phonemics and pronunciation tests. The Modern Language Journal, 35(7), 531-542. https://doi.org/10.1111/j.1540-4781.1951.tb01646.x

leCompte, M., \& Schensul, J. (1999). Essential Ethnographic Methods (vol. 2): Ethnographers Toolkit. NY: Altamira press.

Lintunen, P. (2004). Pronunciation and phonemic transcription: a study of advanced Finnish learners of English. Turku, Finland: University of Turku.

Long, M. H. (1990). Maturational constraints on language development. Studies in Second Language Acquisition, 12, 251-285. https://doi.org/10.1017/S0272263100009165

Long, M. H. (1993). Second language acquisition as a function of age: research findings and methodological issues. K. Hyltenstam, Å. Viberg (Eds.), Progression and Regression in Language. Cambridge: CUP.

Milovanov, R., Pietilä, P., Tervaniemi M., \& Esquef, P. A. A. (2010). Foreign language pronunciation skills and musical aptitude: A study of Finnish adults with higher education. Learning and Individual Differences 20, 56-60. https://doi.org/10.1016/j.lindif.2009.11.003 
Murkoff, H. (2017, October 13). Fetal Sense of Hearing: What Your Baby Can Hear in Utero. Retrieved from https://www.whattoexpect.com/pregnancy/fetal-development/fetal-hearing/

Omrod, J. E. (2014). Educational psychology developing learners. Boston: Pearson Education Limited.

PICTES, (2018). Project for supporting the integration of Syrian children into Turkish education system. Ministry of National Education. Author (MoNE). Retrieved from: https://pictes.meb.gov.tr/izleme

Republic of Turkey Ministry of Interior (2017). 2016 Turkey migration report. Ankara: Directorate General of Migration Management. Author. Retrieved from http://www.goc.gov.tr/files/files/2016_goc_raporu_.pdf

Saunders, M., Lewis, P., \& Thornhill, A. (2012). Research methods for business students ( $6^{\text {th }}$ ed.) Harlow: Pearson Education Limited.

Scovel, T. (1988). A time to speak: A psycholinguistic inquiry into the critical period for human speech. New York: Newbury House.

Şengül, K. (2014). Alphabet issues in teaching Turkish as a foreign language. International Journal of Turkish Literature Culture Education (TLCE) 3(1), 325-339. https://doi.org/10.7884/teke.245

Şimsek, H., \& Yıldırım, A. (2005). Qualitative research methods in the social sciences. Ankara: Seçkin Publishing.

Singley, M. K., \& Anderson, J. R. (1989). The transfer of cognitive skill. Cambridge, MA: Harvard University Press.

Sönmez, V., \& Alacapınar, F. G. (2011). Exemplified scientific research methods. Ankara: Anı Publishing.

Timmons, J. (2018, January 05). When Can a Fetus Hear? Healthline: Retrieved from https://www.healthline.com/health/pregnancy/when-can-a-fetus-hear

Tunçel, H. (2015). Examination of Turkish as a foreign language speaking anxiety in terms of some variables. Hacettepe University Journal of Turkish Studies 2, 107-135. Retrieved from: http://www.turkiyat.hacettepe.edu.tr/huydotad/huydotad_2sayi.pdf

Wiik, K. (1965). Finnish and English Vowels. Turku: University of Turku.

Woltz, D. J., Gardner, M. K., \& Bell, B. G. (2000). Negative transfer errors in sequential cognitive skills: Strong-but-wrong sequence application. Journal of Experimental Psychology: Learning, Memory, and Cognition, 26(3), 601-635. https://doi.org/10.1037/0278-7393.26.3.601

Yılmaz, İ., \& Şeref, İ. (2015). Using poetry in developing Arabian students' pronunciation skills while reading. International Journal of Turkish Literature Culture Education (TLCE) 4(3), 1213-1228. https://doi.org/10.7884/teke.542

Zorn, T. (2010). Designing and Conducting Semi-Structured Interviews for research. Retrieved from http://home.utah.edu/ u0326119/Comm4170-01/resources/Interviewguidelines.pdf

\section{Copyrights}

Copyright for this article is retained by the author(s), with first publication rights granted to the journal.

This is an open-access article distributed under the terms and conditions of the Creative Commons Attribution license which permits unrestricted use, distribution, and reproduction in any medium, provided the original work is properly cited. 